\title{
OS 200 ANOS DA PILHA ELÉTRICA
}

\author{
Aécio Pereira Chagas \\ Instituto de Química - Universidade Estadual de Campinas - CP 6154 - 13083-970 - Campinas - SP
}

Recebido em 21/10/99; aceito em 15/3/00

\begin{abstract}
THE 200 YEARS OF THE ELECTRIC PILE. In celebration of the $200^{\text {th }}$ anniversary of the electric pile, invented by Alessandro Volta, a synopsis of his letter to The Royal Society (London) and of his biography is presented.
\end{abstract}

Keywords: electric pile; Volta; history of science.

No final de 1799, Alessandro Volta concluiu seu trabalho sobre o que ele chamou de "órgão elétrico artificial", hoje mais conhecido como pilha elétrica. Em 20 março de 1800 ele escreve uma carta a Sir Joseph Banks, presidente da Royal Society of London, comunicando estes resultados, sendo lida na referida sociedade em 26 de junho e publicada no número de setembro do Philosophical Transactions ${ }^{1}$. Daí as comemorações do bicentenário desta fabulosa invenção serem em 1999 ou em 2000.

A carta de Volta era em francês e assim foi publicada, acrescida apenas com um título em inglês: On the Electricity excited by the mere Contact of conducting Substances of different kinds. In a Letter from Mr. Alexander Volta, F. R. S. Professor of Natural Philosophy in the University of Pavia, to the Rt. Hon. Sir Joseph Banks, Bart. K. B. P. R. S. [sic] ${ }^{1}$. No mesmo ano o Philosophical Magazine publica uma tradução da mesma para o inglês ${ }^{2}$.

O "órgão elétrico artificial" foi o resultado de uma controvérsia entre Volta e seu compatriota Luigi Galvani (1737-1798) ${ }^{3-6}$. Este último havia descoberto, em torno de 1780, que quando se tocava uma extremidade de um músculo, dissecado da perna de uma rã, com um metal e a outra extremidade com outro metal diferente, ao se pôr em contacto dos dois metais o músculo se contraía. Sem se deter nas motivações de Galvani e em seus estudos, chegou ele a conclusão que o efeito era devido ao músculo, por ele possuir "eletricidade animal" (na época eram considerados vários tipos de eletricidade). Volta foi de opinião que a causa da contração era o contacto dos diferentes metais e seu "órgão elétrico artificial" foi construído para confirmar seus pontos de vista. De fato, um de seus dispositivos era constituído de uma série de discos de dois metais diferentes, como prata e zinco, empilhados (daí o nome pilha) alternativamente (ver a reprodução da gravura, Figuras 2, 3 e 4). Entre cada disco havia um pedaço de tecido ou papel embebido com água, água com sal (cloreto de sódio) ou com líxívia (carbonato de potássio, principalmente). Além da prata podiam ser utilizados outros metais como cobre, estanho ou chumbo, sendo que das diferentes combinações, prata e zinco davam os melhores resultados. Um outro tipo de montagem, que ele denomina couronné de tasses (cadeia de copos), é também apresentada (Figura 1 na reprodução da gravura). Em sua carta a Royal Society, Volta descreve os efeitos obtidos com esta fonte de eletricidade, que ele considerava um tipo de movimento perpétuo, nos vários órgãos dos sentidos (língua, olhos, mãos, nariz, ouvido), mostrando que em todos os casos havia a percepção de um efeito no respectivo órgão, exceto no nariz, onde não se percebia nenhuma sensação de odor. Entretanto, comenta ele, havia, nas

aecio@iqm.unicamp.br. descargas elétricas produzidas pelos contacto dos fios metálicos ligados a seu aparelho, a produção de odores. No final da comunicação Volta mostra certa semelhança de forma entre os discos empilhados com os órgão elétrico do torpedo ou peixe-elétrico, justificando assim o nome dado.

Antes mesmo da carta de Volta ser publicada, em maio de 1800, William Nicholson (1753-1815) e Anthony Carlisle (1768-1840) constroem uma pilha e realizam a eletrólise da água. O primeiro era secretário da Royal Society. Em julho de 1800, William Cruickshanks (1745-1800), também em Londres, realiza a primeira eletrodeposição de um metal ${ }^{7-10}$.

Alessando Giuseppe Anastasio Volta nasceu em 18 de fevereiro de 1745, em Como, próximo a Milão (Itália). Filho de família aristocrática, não teve educação formal. Um de seus professores, Padre Carlo Giuseppe Campi, chamou sua atenção para o gás que se desprendia nos pântanos próximos a sua cidade, e o jovem Volta realiza um estudo desse gás, publicando-o na forma de sete cartas - Lettere sull'aria infiammabile nativa delle paludi - durante 1776 e 1777. Por isto Volta é considerado o descobridor do metano (gás dos pântanos). Realizou diversos e importantes trabalhos em Química Pneumática (Química dos gases), tornando-se um dos destacados químicos da época. Ele inventa também a pistola elétrica e aperfeiçoa o eudiômetro. O primeiro dispositivo é um tubo com uma tampa, não presa, na parte superior e com dois fios próximos na parte inferior. Este tubo era cheio com uma mistura de gases, por exemplo metano e ar. O contacto dos fios com os pólos de uma garrafa de Leyden (um tipo de capacitor elétrico usado na época) produzia uma faísca, dentro do tubo, explodindo a mistura gasosa, que lançava a tampa a uma certa distância. Com este dispositivo Volta determinou a melhor relação hidrogênio e oxigênio para a combustão (1 volume de hidrogênio com 2 volumes de oxigênio), através da medida da distância de lançamento da tampa. Assim também o fez para o metano e, neste caso, a relação foi 1 volume de metano com 8 a 12 volumes de oxigênio. Utilizou também o ar. $\mathrm{O}$ eudiômetro é um aparelho utilizado para analisar gases através da combustão, medindo-se os volumes das misturas gasosas antes e depois desta reação. O nome eudiômetro, criado por Marsilio Landriani (1756-1815) em 1775, significa "aparelho para medir o grau de saúde do ar". Volta tornou o eudiômetro um aparelho de elevada precisão. Graças a estes trabalhos, elogiados pelos mais eminentes químicos da época (Priestley, Lavoisier, Cavendish, Berthollet e outros), Volta foi nomeado professor de Fisica Sperimentale da Universidade de Pavia, sem ter nunca cursado uma universidade. Foi indicado membro de várias academias de ciências da Europa: Haarlem, Paris, Pavia, Turim, Munique, Berlin, Mantua, Londres (Royal Society), Bolonha e outras. Napoleão Bonaparte, um de seus admiradores, que além de Imperador da França era também 


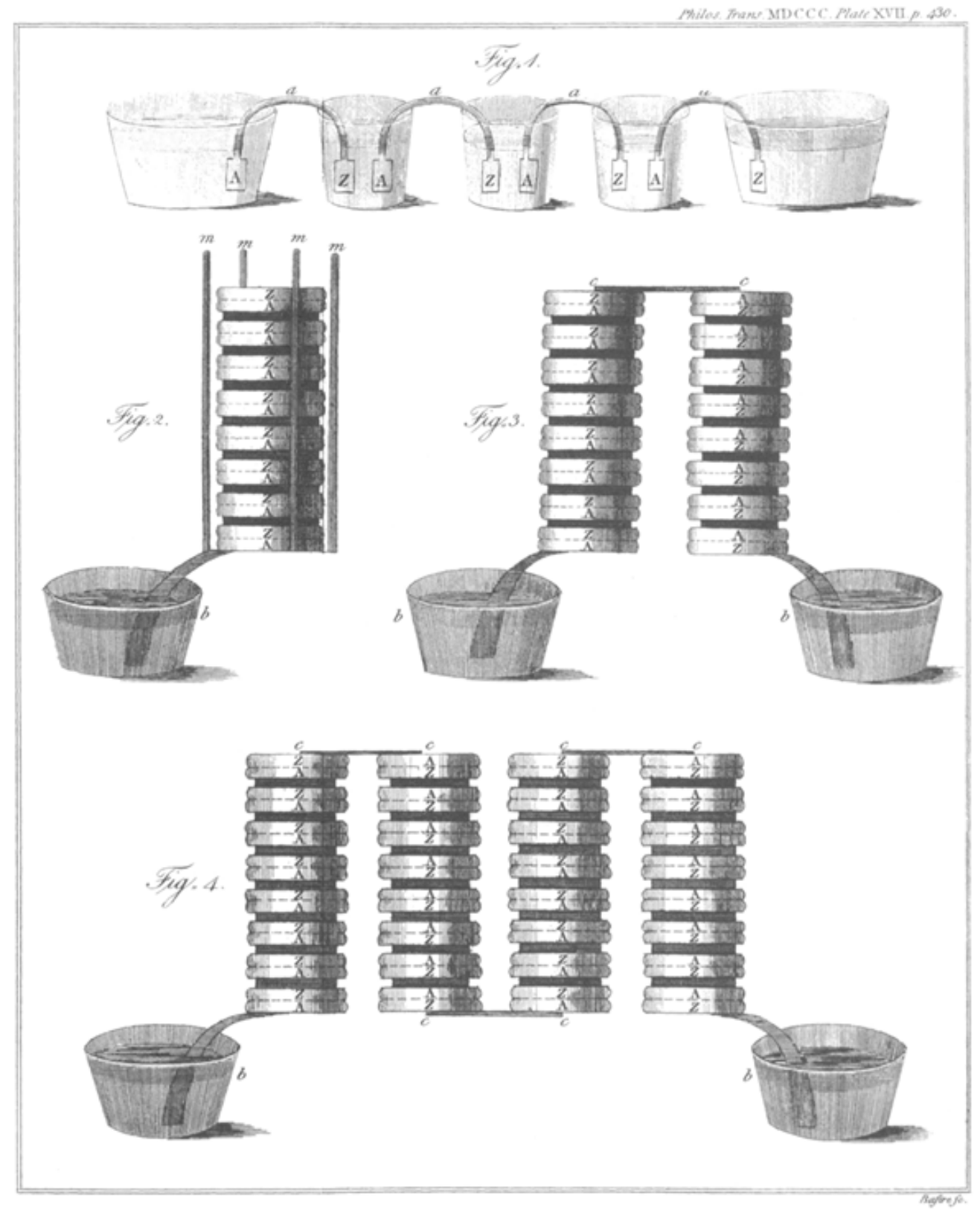

Reprodução da gravura constante no artigo de Volta (ref. 1, p 430).

Rei da Itália, outorgou-lhe o título de Conde Volta. Volta falece em 5 de março de 1827, em Como, com $82 \operatorname{anos}^{7,10}$.

Desnecessário dizer sobre a importância da pilha elétrica para a Ciência, para a Técnica e para toda a Humanidade. Sem ela não teria sido possível o "mundo elétrico" de hoje. Logo após a sua comunicação, muitos pesquisadores passaram a construir suas pilhas e a utilizá-las, pois, mesmo para a época, era relativamente fácil sua construção: "Bastavam algumas moedas de cobre, alguns pedaços de zinco e um pouco de ácido ... e pronto!", não requerendo grandes investimentos. Interessante citar o fato que Volta considerava que seu órgão elétrico artificial produzia, no fluido elétrico, um movimento perpétuo ... e não foi fácil mostrar que ele estava enganado. Isto levou vários anos de polêmicas ${ }^{3}$.

Das pesquisas que se desenvolveram posteriormente com a pilha elétrica, podemos considerá-las de dois ângulos: no primeiro ângulo as pesquisas com as próprias pilhas, procurandose aperfeiçoá-las, conhecer as causas dos fenômenos observados (por exemplo, mostrar que a causa da corrente era a reação química que ocorria entre os materiais da pilha e não apenas através do contacto dos metais, como pensava Volta) etc. Podese também destacar que o estudo da pilha foi o fundamento da teoria da ligação química de Berzelius (Teoria Dualística), foi uma das vertentes que levou ao estabelecimento da Primeira Lei da Termodinâmica (conservação da energia) e, mais tarde, foi utilizada para mostrar que a Segunda Lei da Termodinâmica também era válida em sistemas com reação química.

$\mathrm{O}$ segundo ângulo a se considerar foi o fato da pilha ser uma fonte de eletricidade duradoura e estável, diferentemente das máquinas eletrostáticas de então. Com a pilha foi possível decompor substâncias, depositar metais, inclusive novos elementos, estudar o comportamento da corrente elétrica e seus efeitos, inclusive magnéticos etc. Foi graças as pilhas que se tornou possível o conhecimento do Eletromagnetismo e da tecnologia correspondente.

Antes de terminar, uma pequena observação: Volta era professor de Fisica Sperimentale e no título de seu trabalho, em inglês, consta: Professor of Natural Philosophy. Estes dois 
termos tinham, na época, o mesmo significado. O objetivo da Filosofia Natural era explicar o mundo, em complementação com a História Natural, que se preocupava em descrevê-lo. O que entendemos hoje por Física e Química estavam sendo formadas naquela época. Ambas, na época, eram partes da Filosofia Natural ${ }^{11,12}$.

\section{REFERÊNCIAS}

1. Volta, A.; Philosophical Transactions 1800, 403.

2. Volta, A.; Phil. Mag. 1800, 7, 289.

3. Whitaker, E.; A History of Theories of Aether and Electricity; Dover Publications, New York, 1989.
4. Piccolino, M.; Trends Neurosci. 1997, 20, 443.

5. Bresadola, M.; Brain Res. Bull. 1998, 46, 367.

6. Piccolino, M.; Brain Res. Bull. 1998, 46, 381.

7. Buldini, P. L., Educ. Chem. 1985, 12.

8. Laidler, K. J.; The World of Physical Chemistry; Oxford University Press, Oxford, 1993.

9. Trasatti, S.; J. Electroanal. Chem. 1999, 460, 1.

10. Millar, D. et al.; The Cambridge Dicionary of Scientists, Cambridge University Press, Cambridge, 1996.

11. Nye, M. J.; From Chemical Philosophy to Theoretical Chemistry; University of California Press, Berkeley (CA), 1993.

12. Theobald, D. W.; Chem. Soc. Rev. 1976, 203. 